\title{
Utilization of Neoadjuvant Intensity-modulated Radiation Therapy for Rectal Cancer in the United States
}

\author{
TAYLOR R. CUSHMAN ${ }^{1}$, SRIRAM VENIGALLA ${ }^{2}$, ERIC D. BROOKS ${ }^{3}$, CHI LIN $^{4}$ and VIVEK VERMA ${ }^{4}$ \\ ${ }^{1}$ University of Arizona College of Medicine-Phoenix, Phoenix, AZ, U.S.A; \\ ${ }^{2}$ Department of Radiation Oncology, University of Pennsylvania School of Medicine, Philadelphia, PA, U.S.A; \\ ${ }^{3}$ Department of Radiation Oncology, University of Texas M.D. Anderson Cancer Center, Houston, TX, U.S.A; \\ ${ }^{4}$ Department of Radiation Oncology, University of Nebraska Medical Center, Omaha, NE, U.S.A.
}

\begin{abstract}
Background/Aim: Advances in technology have expanded the use of intensity-modulated radiotherapy (IMRT). The goal of this study was to investigate trends in the utilization of IMRT for rectal cancer (RC) in USA. Materials and Methods: The National Cancer Database was queried for RC patients receiving neoadjuvant chemoradiotherapy with either IMRT or three-dimensional conformal radiation therapy (3DCRT). Differences in factors associated with receipt of $3 D C R T$ versus $I M R T$ were determined and temporal trends were analyzed. Results: From 2005 to 2009, IMRT utilization increased, but remained constant and roughly equivalent to $3 D C R T$ from 2010 to 2014. Patients who received IMRT were more likely to have T4 disease $(p=0.014)$, while patients diagnosed in 2004-2006 $(p<0.0001)$ and 2007-2008 $(p=0.015)$ were less likely to receive IMRT. There were no significant differences in postoperative outcomes between patients receiving $3 D C R T$ and IMRT. Conclusion: IMRT utilization initially increased, but is now used at similar frequencies to 3DCRT and offers similar shortterm postoperative outcomes.
\end{abstract}

The current standard-of-care for locally advanced rectal cancer (RC) is neoadjuvant chemoradiotherapy (CRT) followed by surgery, with or without adjuvant chemotherapy (CT) (1). Although optimal timing of chemotherapy is still controversial, neoadjuvant radiotherapy (RT) is preferred over adjuvant RT $(2,3)$.

Gastrointestinal and genitourinary toxicities may occur as a result of RT use, with ample data describing this in the context of three-dimensional conformal radiation therapy

Correspondence to: Vivek Verma, MD, Department of Radiation Oncology, University of Nebraska Medical Center Fred \& Pamela Buffett Cancer Center, 505 S. 45th St., Omaha, NE 68106, U.S.A. Tel: +1 4025523844, Fax: +1 4025523013, e-mail: vivek333@gmail.com

Key Words: Rectal cancer, radiation therapy, intensity modulated radiotherapy.
(3DCRT) (2-4). However, advancements in modern technology have led to the emergence of intensity-modulated radiation therapy (IMRT), which offers more conformal treatment and may result in fewer toxicities (5-8). Comparative retrospective data have shown significantly decreased toxicities with IMRT $(7,9)$. Furthermore, multiple prospective non-randomized trials using IMRT for $\mathrm{RC}$ have reported encouraging survival and toxicity outcomes (10-12).

Despite this positive evidence, the use of IMRT remains controversial. Consensus American Society for Radiation Oncology (ASTRO) guidelines recommend that IMRT "May Be Appropriate" in the neoadjuvant and adjuvant settings for RC (13). Given the controversy regarding its role in treatment of RC, national patterns of utilization of IMRT are unclear. Thus, the goal of this study was to evaluate the utilization of neoadjuvant IMRT for RC in the United States.

\section{Materials and Methods}

This retrospective study analyzed the National Cancer Data Base (NCDB), which is a jointly sponsored database by the Commission on Cancer (CoC) of the American College of Surgeons (ACS) and the American Cancer Society. Data includes de-identified information regarding first-course treatments and outcomes from approximately $70 \%$ of all malignant cancers diagnosed at $\mathrm{CoC}$ accredited facilities within the United States. All patient data in the NCDB are de-identified and therefore were exempt from review by an institutional review board.

The NCDB dataset used for analysis corresponded to the years 2004-2015. Inclusion criteria for this study were patients $\geq 18$ years with T1-T4 N0-3 M0 RC with histologically confirmed adenocarcinoma (International Classification of Disease for Oncology [ICD-O-3] histologic codes: 8140, 8211, 8213, 8240, $8244,8261,8263,8480,8510$, and 8560 ) treated with neoadjuvant radiation therapy followed by surgery. As we intended to compare use of neoadjuvant IMRT versus 3DCRT, patients without a documented RT technique were excluded. Demographic, clinicopathologic, and treatment facility characteristics were collected for each patient. The overall cohort was divided into two study cohorts: 1) those who received 3DCRT prior to surgery, and 2) those who received IMRT prior to surgery. 


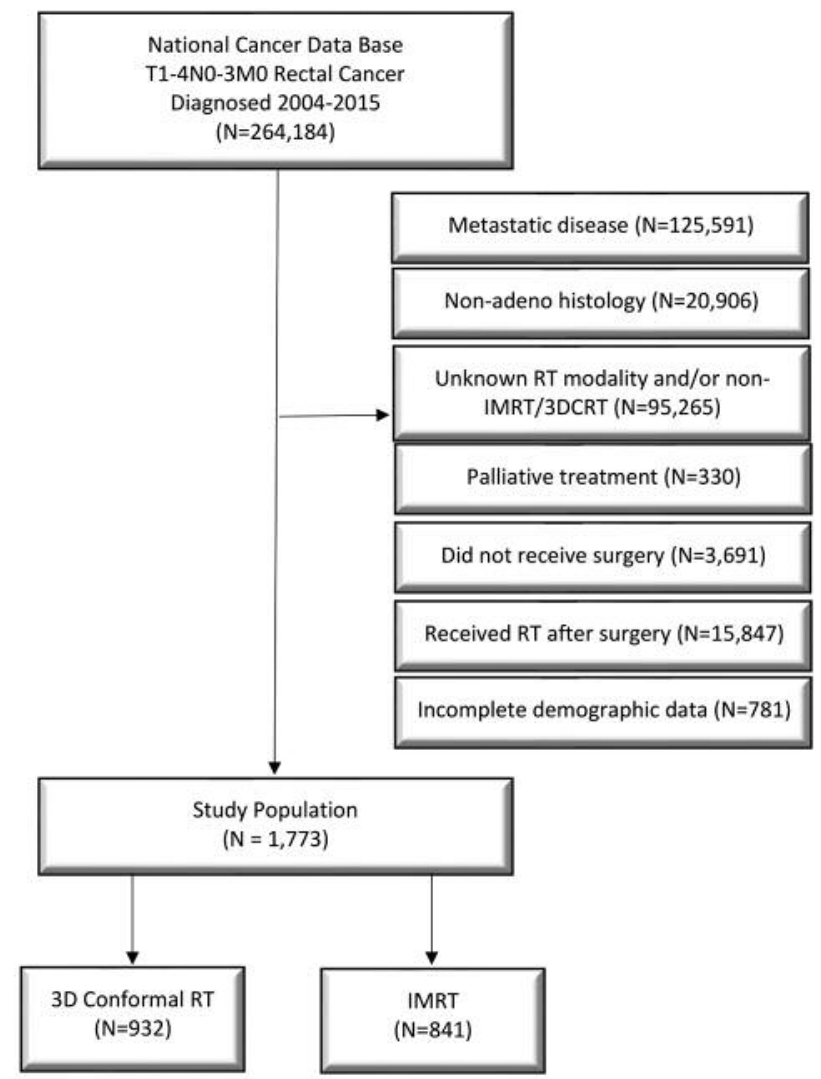

Figure 1. Patient selection diagram.

The primary goal was to evaluate temporal trends and predictors of IMRT use.

Baseline characteristics were compared between IMRT and 3DCRT cohorts using $\chi^{2}$ or Fisher's exact tests (non-parametric and parametric settings, respectively), multivariable logistic regression modeling was utilized to determine characteristics predictive for IMRT receipt. Thirty-day readmission and 30-day/90-day postoperative mortality rates were compared using Fisher's exact test, and length of post-operative hospital stay was compared with the Mann-Whitney $U$-test. All statistical tests were two-sided, with a threshold of $p<0.05$ for statistical significance and were performed using IBM SPSS Statistics (version 24).

\section{Results}

A total of 1,773 patients were identified per study inclusion criteria (Figure 1). Use of 3DCRT and IMRT were $81 \%$ and $19 \%$, respectively, in 2004. There was an increase in IMRT use from $2005-2009$ from $12 \%$ to $58 \%$ along with a corresponding decrease in 3DCRT from $88 \%$ to $42 \%$ (Figure 2). From 20102014 , both RT techniques were utilized at similar rates.

Table I displays baseline characteristics of the study cohorts. On multivariable analysis, patients treated with 3DCRT versus IMRT were less likely to have T4 disease

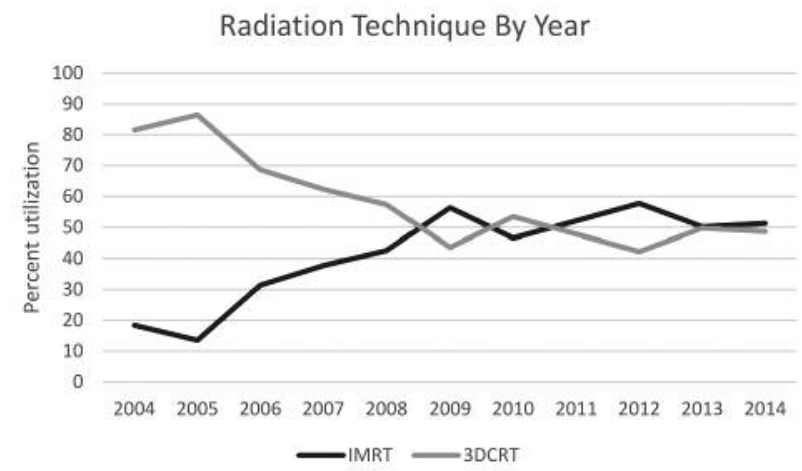

Figure 2. Temporal trends in IMRT and 3DCRT utilization.

relative to $\mathrm{T} 1$ disease (Odds ratio (OR), $0.53 ; 95 \%$ confidence interval $(\mathrm{CI}), 0.32-0.88 ; p=0.014)$ and receive treatment in the West South-Central USA (Texas, Oklahoma, Arkansas, and Louisiana) relative to New England $(\mathrm{OR}=0.33$; $95 \% \mathrm{CI}=0.19-0.63 ; p=0.001)$. Patients were more likely to receive 3DCRT compared to IMRT if diagnosed in 2004$2006(\mathrm{OR}=3.40 ; 95 \% \mathrm{CI}=2.27-5.08 ; p<0.001)$ or $2007-2008$ $(\mathrm{OR}=1.46 ; 95 \% \mathrm{CI}=1.08-1.99 ; p=0.015)$. Of note, there were no differences between groups with regard to socioeconomic or insurance-related parameters ( $p>0.05$ for all).

Because the NCDB records post-operative 30-day readmission, 30-day mortality, 90-day mortality, and length of hospital stay, these data were compared between the IMRT and 3DCRT cohorts. Comparing 3DCRT to IMRT, there were no significant differences in median postoperative days to discharge ( 5 days for both, $p=0.136$ ), 30 day readmission rate ( $8 \%$ for both, $p=0.76$ ), or $30 / 90$-day mortality rate ( $1 \%$ for all, $p=0.928$ and 0.839 , respectively).

\section{Discussion}

The use of pre-operative 3DCRT remains the standard-ofcare for treatment of non-metastatic RC, owing to the vast majority of available prospective trials having utilized this technique. However, modern series have utilized IMRT and have noted favorable toxicity data as compared to those of historical 3DCRT studies. In this investigation, we observed a dramatic increase in the use of IMRT from the 2004-2009, with roughly equal use of IMRT and 3DCRT thereafter. Along with regional differences, patients with $\mathrm{T} 4$ disease were more likely to receive IMRT. Readmission rates, mortality, and length of post-operative hospital stay were comparable between study cohorts.

The increased likelihood of receiving IMRT in patients with $\mathrm{T} 4$ disease may be explained by the need to treat the external iliac lymph nodes given the advanced extent of 
Table I. Characteristics of the patients within each treatment group and multivariable logistic regression analysis evaluating predictors of receiving $3 D C R T$.

\begin{tabular}{|c|c|c|c|c|}
\hline \multirow[t]{2}{*}{ Parameter } & \multirow[t]{2}{*}{ IMRT (N=841) } & \multirow[t]{2}{*}{ 3DCRT (N=932) } & \multicolumn{2}{|c|}{ Multivariable } \\
\hline & & & OR $(95 \% \mathrm{CI})$ & $p$-Value \\
\hline \multicolumn{5}{|l|}{ Age (years) } \\
\hline Median (range) & $64(40-90)$ & $62(40-90)$ & $1.01(0.99-1.02)$ & 0.426 \\
\hline \multicolumn{5}{|l|}{ Gender } \\
\hline Male & $507(60 \%)$ & $553(59 \%)$ & REF & REF \\
\hline Female & $334(40 \%)$ & $379(41 \%)$ & $0.99(0.81-1.21)$ & 0.934 \\
\hline \multicolumn{5}{|l|}{ Race } \\
\hline White & $736(88 \%)$ & $825(88 \%)$ & REF & REF \\
\hline Black & $70(8 \%)$ & $74(8 \%)$ & $1.11(0.76-1.61)$ & 0.606 \\
\hline Other & $35(4 \%)$ & $33(4 \%)$ & $0.89(0.53-1.49)$ & 0.650 \\
\hline \multicolumn{5}{|l|}{ T stage } \\
\hline $\mathrm{T} 1$ & $215(26 \%)$ & $264(28 \%)$ & REF & REF \\
\hline $\mathrm{T} 2$ & $244(29 \%)$ & $269(29 \%)$ & $0.90(0.69-1.17)$ & 0.411 \\
\hline T3 & $330(39 \%)$ & $367(39 \%)$ & $0.88(0.68-1.13)$ & 0.306 \\
\hline $\mathrm{T} 4$ & $52(6 \%)$ & $32(4 \%)$ & $0.53(0.32-0.88)$ & 0.014 \\
\hline \multicolumn{5}{|l|}{$\mathrm{N}$ stage } \\
\hline No & $609(72 \%)$ & $680(73 \%)$ & REF & REF \\
\hline $\mathrm{N}+$ & $232(28 \%)$ & $252(27 \%)$ & $0.96(0.76-1.21)$ & 0.727 \\
\hline \multicolumn{5}{|l|}{ Charlson Deyo score } \\
\hline 0 & $630(75 \%)$ & $708(76 \%)$ & REF & REF \\
\hline 1 & $160(19 \%)$ & $175(19 \%)$ & $1.05(0.81-1.35)$ & 0.725 \\
\hline$\geq 2$ & $51(6 \%)$ & $49(5 \%)$ & $0.97(0.63-1.49)$ & 0.873 \\
\hline \multicolumn{5}{|l|}{ Insurance type } \\
\hline Uninsured & $20(2 \%)$ & $36(4 \%)$ & $0.92(0.67-1.25)$ & 0.577 \\
\hline Private & $360(43 \%)$ & $471(51 \%)$ & $0.91(0.66-1.25)$ & 0.555 \\
\hline Medicaid/other government & $75(9 \%)$ & $47(5 \%)$ & $1.07(0.77-1.49)$ & 0.673 \\
\hline Medicare & $386(46 \%)$ & $378(40 \%)$ & REF & REF \\
\hline \multicolumn{5}{|l|}{ Income (US dollars/year) } \\
\hline$<\$ 30,000$ & $146(17 \%)$ & $157(17 \%)$ & REF & REF \\
\hline$\$ 30,000-\$ 34,999$ & $226(27 \%)$ & $234(25 \%)$ & $0.92(0.68-1.27)$ & 0.622 \\
\hline$\$ 35,000-\$ 45,999$ & $238(28 \%)$ & $253(27 \%)$ & $0.90(0.65-1.24)$ & 0.518 \\
\hline$\geq \$ 46,000$ & $231(28 \%)$ & $288(31 \%)$ & $1.04(0.75-1.45)$ & 0.807 \\
\hline \multicolumn{5}{|l|}{ Patient residence } \\
\hline Metro & $701(83 \%)$ & $757(81 \%)$ & REF & REF \\
\hline Rural & $123(15 \%)$ & $148(16 \%)$ & $1.05(0.77-1.41)$ & 0.775 \\
\hline Urban & $17(2 \%)$ & $27(3 \%)$ & $1.31(0.67-2.56)$ & 0.437 \\
\hline \multicolumn{5}{|l|}{ Facility location } \\
\hline New England & $36(4.3 \%)$ & $48(5 \%)$ & REF & REF \\
\hline Middle Atlantic & $143(17 \%)$ & $114(12 \%)$ & $0.62(0.37-1.04)$ & 0.071 \\
\hline South Atlantic & $191(23 \%)$ & $184(20 \%)$ & $0.77(0.46-1.27)$ & 0.297 \\
\hline East North Central & $138(16 \%)$ & $251(27 \%)$ & $1.45(0.88-2.40)$ & 0.143 \\
\hline East South Central & $40(5 \%)$ & $62(7 \%)$ & $1.26(0.68-2.34)$ & 0.465 \\
\hline West North Central & $88(11 \%)$ & $100(11 \%)$ & $0.87(0.50-1.49)$ & 0.603 \\
\hline West South Central & $63(8 \%)$ & $26(3 \%)$ & $0.33(0.17-0.63)$ & 0.001 \\
\hline Mountain & $49(6 \%)$ & $49(5 \%)$ & $0.84(0.46-1.55)$ & 0.579 \\
\hline Pacific & $93(11 \%)$ & $98(10 \%)$ & $0.89(0.52-1.53)$ & 0.699 \\
\hline \multicolumn{5}{|l|}{ Facility type } \\
\hline Academic & $231(28 \%)$ & $243(26 \%)$ & REF & REF \\
\hline Community & $610(62 \%)$ & $689(64 \%)$ & $0.99(0.78-1.24)$ & 0.908 \\
\hline \multicolumn{5}{|l|}{ Distance to treating facility (mi) } \\
\hline Median (IQR) & $9.4(4.0-23.4)$ & $9.8(4.4-21.8)$ & $1.00(0.99-1.00)$ & 0.623 \\
\hline \multicolumn{5}{|l|}{ Year of Diagnosis } \\
\hline 2004-2006 & $42(5 \%)$ & $141(15 \%)$ & $3.40(2.27-5.08)$ & $<0.001$ \\
\hline $2007-2008$ & $118(14 \%)$ & $172(18 \%)$ & $1.46(1.08-1.99)$ & 0.015 \\
\hline $2009-2010$ & $214(25 \%)$ & $201(22 \%)$ & $0.97(0.74-1.28)$ & 0.829 \\
\hline 2011-2012 & $234(28 \%)$ & $192(21 \%)$ & $0.89(0.67-1.16)$ & 0.381 \\
\hline 2013-2014 & $233(28 \%)$ & $226(24 \%)$ & REF & REF \\
\hline
\end{tabular}

Statistically significant $p$-Values $(<0.05)$ are in bold. OR: Odds ratio; CI: confidence interval. 
disease. Compared to 3DCRT, IMRT is able to better spare organs at risk from high dose radiation in the treatment of inguinal lymph nodes (14) and may therefore result in lower rates of bowel toxicity $(7,9)$. Also, as T4 RC may involve invasion of important organs such as the left kidney, prostate, colon, and cervix, IMRT may be used in efforts to spare uninvolved portions of these organs.

The temporal increase in IMRT utilization from 20052009, was likely due to adoption and implementation of the new technology around that time. The stabilization of IMRT usage starting after 2009 may be attributable to several obstacles, including lack of long term data, insurance reimbursement issues (although, notably, patient insurance coverage was not an independent predictor of RT technique), and increased interest in other technologies. Despite a lack of statistical significance, insurance reimbursement may have been different by region, which would also offer an explanation for regional differences in treatment. Because we analyzed groups as a whole, we were unable to rule out regionally-related insurance coverage.

In a single institution retrospective analysis comparing post-operative outcomes in RC patients who received IMRT versus 3DCRT, significantly fewer hospitalizations in the IMRT group were reported (15). A lack of a similar finding in our study may be partially attributable to dissimilar patient populations. The aforementioned publication excluded patients with $\mathrm{T} 1$ disease, while our cohort consisted of nearly $30 \%$ of patients with $\mathrm{T} 1$ disease; more of their patients had preoperative $\mathrm{N}+$ stage and metastatic disease. Although not reported, it is possible that their cohort had a higher proportion of distal rectal tumors, which may have necessitated treatment of the inguinal lymph nodes, and thus could have increased the incidence of Gastrointestinal (GI) and Genitourinary (GU) toxicities. The NCDB does not record tumor location or toxicity endpoints, so this evaluation cannot be conclusively made in our study.

Randomized, prospective evidence is warranted to provide a definitive answer as to whether neoadjuvant IMRT is superior to 3DCRT in RC. However, phase III data assessing a similar issue in gynecologic cancers shows that IMRT was superior to 3DCRT in terms of acute GI and GU toxicity and quality of life measures (16). The study used radiation doses of 45-50.4 Gy, which is approximately equal to doses used for RC cases. Taken as a whole, it is plausible that patients with RC would experience comparable results.

Although the NCDB is a valuable resource with which to study this important clinical question, there are inherent limitations to this study. First, NCDB investigations are, by definition, retrospective and are therefore vulnerable to selection bias. Although the NCDB captures an estimated 70\% of the cancer patient population in USA, only CoC-accredited institutions are able to contribute data. As a result, the data may be missing important subpopulations within USA. A large proportion of this dataset did not have proper coding of RT technique (e.g. missing values), which is another important shortcoming that may have biased results. Lastly, the NCDB does not collect data on several key RT variables, including radiation field design/volumes, which chemotherapeutic regimens were used, or patient-reported toxicities/quality of life measures. Hence, although the postoperative parameters given by the NCDB were similar between groups, the lack of other endpoints limits firm conclusions.

\section{Conclusion}

In this retrospective, observation study using the NCDB, a dramatic increase is demonstrated in the use of IMRT from the mid- through late 2000 s, with a roughly equal use of IMRT and 3DCRT thereafter. Regional differences and T4 disease were associated with an increased likelihood of receipt of IMRT. There were no differences in readmission rates, mortality, and length of post-operative hospital stay between patients who received 3DCRT or IMRT. These results suggest that IMRT is a safe and comparable alternative to 3DCRT. Prospective data are needed to further assess long-term outcomes.

\section{Conflicts of Interest}

This study has never been presented/published before in any form. All Authors declare that conflicts of interest do not exist.

\section{References}

1 National Comprehensive Cancer Network: Rectal Cancer. Version 1, 2018. Available from: https://www.nccn.org/patients/ guidelines/rectal/files/assets/common/downloads/files/rectal.pdf [Last accessed March 26 2018].

2 Sauer R, Liersch T, Merkel S, Fietkau R, Hohenberger W, Hess C, Becker H, Raab HR, Villanueva MT, Witzigmann H, Wittekind C, Beissbarth T and Rodel C: Preoperative versus postoperative chemoradiotherapy for locally advanced rectal cancer: results of the German CAO/ARO/AIO-94 randomized phase III trial after a median follow-up of 11 years. J Clin Oncol 30: 1926-1933, 2012.

3 Roh MS, Colangelo LH, O'Connell MJ, Yothers G, Deutsch M, Allegra CJ, Kahlenberg MS, Baez-Diaz L, Ursiny CS, Petrelli $\mathrm{NJ}$, and Wolmark N: Preoperative multimodality therapy improves disease-free survival in patients with carcinoma of the rectum: NSABP R-03. J Clin Oncol 27: 5124-5130, 2009.

4 Baglan KL, Frazier RC, Yan D, Huang RR, Martinez AA and Robertson JM: The dose-volume relationship of acute small bowel toxicity from concurrent 5-FU-based chemotherapy and radiation therapy for rectal cancer. Int J Radiat Oncol Biol Phys 52: 176-183, 2002

5 Guerrero Urbano MT, Henrys AJ, Adams EJ, Norman AR, Bedford JL, Harrington KJ, Nutting CM, Dearnaley DP and Tait DM: Intensity-modulated radiotherapy in patients with locally advanced rectal cancer reduces volume of bowel treated to high dose levels. Int J Radiat Oncol Biol Phys 65: 907-916, 2006. 
6 Arbea L, Ramos LI, Martinez-Monge R, Moreno M and Aristu J: Intensity-modulated radiation therapy (IMRT) vs. 3D conformal radiotherapy (3DCRT) in locally advanced rectal cancer (LARC): dosimetric comparison and clinical implications. Radiat Oncol 5: 17, 2010.

7 Samuelian JM, Callister MD, Ashman JB, Young-Fadok TM, Borad MJ, and Gunderson LL: Reduced acute bowel toxicity in patients treated with intensity-modulated radiotherapy for rectal cancer. Int J Radiat Oncol Biol Phys 82: 1981-1987, 2012.

8 Tho LM, Glegg M, Paterson J, Yap C, MacLeod A, McCabe M and McDonald AC: Acute small bowel toxicity and preoperative chemoradiotherapy for rectal cancer: Investigating dose-volume relationships and role for inverse planning. Int J Radiat Oncol Biol Phys 66: 505-513, 2006.

9 Ng SY, Colborn KL, Cambridge L, Hajj C, Yang TJ, Wu AJ and Goodman KA: Acute toxicity with intensity modulated radiotherapy versus 3-dimensional conformal radiotherapy during preoperative chemoradiation for locally advanced rectal cancer. Radiother Oncol 121: 252-257, 2016.

10 Hong TS, Moughan J, Garofalo MC, Bendell J, Berger AC, Oldenburg NB, Anne PR, Perera F, Lee RJ, Jabbour SK, Nowlan A, DeNittis A and Crane C: NRG Oncology Radiation Therapy Oncology Group 0822: A Phase 2 Study of Preoperative Chemoradiation Therapy Using Intensity Modulated Radiation Therapy in Combination With Capecitabine and Oxaliplatin for Patients With Locally Advanced Rectal Cancer. Int J Radiat Oncol Biol Phys 93: 29-36, 2015.

11 Tey J, Leong CN, Cheong WK, Sze TG, Yong WP, Tham IWK and Lee KM: A phase II trial of preoperative concurrent chemotherapy and dose escalated intensity modulated radiotherapy (IMRT) for locally advanced rectal cancer. J Cancer 8: 3114-3121, 2017.

12 But-Hadzic J, Anderluh F, Brecelj E, Edhemovic I, SecerovErmenc A, Hudej R, Jeromen A, Kozelj M, Krebs B, Oblak I, Omejc M, Vogrin A and Velenik V: Acute Toxicity and Tumor Response in Locally Advanced Rectal Cancer After Preoperative Chemoradiation Therapy With Shortening of the Overall Treatment Time Using Intensity-Modulated Radiation Therapy With Simultaneous Integrated Boost: A Phase 2 Trial. Int J Radiat Oncol Biol Phys 96: 1003-1010, 2016.
13 Goodman KA, Patton CE, Fisher GA, Hoffe SE, Haddock MG, Parikh PJ, Kim J, Baxter NN, Czito BG, Hong TS, Herman JM, Crane $\mathrm{CH}$ and Hoffman KE: Appropriate customization of radiation therapy for stage II and III rectal cancer: Executive summary of an ASTRO Clinical Practice Statement using the RAND/UCLA Appropriateness Method. Pract Radiat Oncol 6: 166-175, 2016.

14 Portelance L, Chao KS, Grigsby PW, Bennet H and Low D: Intensity-modulated radiation therapy (IMRT) reduces small bowel, rectum, and bladder doses in patients with cervical cancer receiving pelvic and para-aortic irradiation. Int $\mathbf{J}$ Radiat Oncol Biol Phys 51: 261-266, 2001.

15 Jabbour SK, Patel S, Herman JM, Wild A, Nagda SN, Altoos T, Tunceroglu A, Azad N, Gearheart S, Moss RA, Poplin E, Levinson LL, Chandra RA, Moore DF, Chen C, Haffty BG and Tuli R: Intensity-modulated radiation therapy for rectal carcinoma can reduce treatment breaks and emergency department visits. Int J Surg Oncol 2012: 891067, 2012.

16 Klopp AH, Yeung AR, Deshmukh S, Gil KM, Wenzel L, Westin SN, Gifford K, Gaffney DK, Small W Jr., Thompson S, Doncals DE, Cantuaria GHC, Yaremko B, Chang A, Kundapur V, Mohan DS, Haas ML, Kim YB, Ferguson CL and Bruner DW: A Phase III randomized trial comparing patient-reported toxicity and quality of life (QOL) during pelvic intensity modulated radiation therapy as compared to conventional radiation therapy. Int $\mathbf{J}$ Radiat Oncol Biol Phys 96: S3, 2016.

Received March 6, 2018

Revised March 23, 2018

Accepted March 26, 2018 